\title{
Custos relacionados ao Centro de Esterilização: Revisão integrativa
}

\author{
Costs related to the Sterilization Center: Integrative review \\ Costos relacionados con el Centro de Esterilización: Revisión integrativa
}

Raíssa Rafaella Santos Moreno da Silva

ORCID: https://orcid.org/0000-0002-7265-9352

Universidade Federal de Alagoas, Brasil E-mail: raissarafaella13@gmail.com

Beatriz Alves Torres

ORCID: https://orcid.org/0000-0002-8607-7468

Universidade Federal de Alagoas, Brasil E-mail: biababinha@gmail.com

Eveline Lucena Vasconcelos

ORCID: https://orcid.org/0000-0003-3522-6248 Universidade Federal de Alagoas, Brasil E-mail: evelinelucena@gmail.com

Jane Keyla Souza dos Santos Macedo ORCID: https://orcid.org/0000-0002-5037-097X Universidade Federal de Alagoas, Brasil E-mail: jkeyla_souza@hotmail.com

Isabel Comassetto

ORCID: https://orcid.org/0000-0002-2389-9384 Universidade Federal de Alagoas, Brasil E-mail: isabelcomassetto@gmail.com

Thaís Honório Lins Bernardo

ORCID: https://orcid.org/0000-0002-8058-8400 Universidade Federal de Alagoas, Brasil E-mail: thais.bernardo@eenf.ufal.br

Thalita Costa Souza

ORCID: https://orcid.org/0000-0002-0645-1035 Universidade Federal de Alagoas, Brasil

E-mail: thcsouza@outlook.com

Thayse Gomes de Almeida

ORCID: https://orcid.org/0000-0001-8747-023X Universidade Federal de Alagoas, Brasil E-mail: thaysegalmeida@gmail.com

Isadora Pereira Farias

ORCID: https://orcid.org/0000-0001-5771-8492 Universidade Federal de Alagoas, Brasil E-mail: isadora.pfarias@gmail.com

\begin{abstract}
Resumo
Objetivo: identificar, através da literatura, os custos relacionados ao CME e propor formas de otimizar tais gastos no âmbito das instituições de saúde atualmente. Método: Estudo de revisão integrativa, por meio de pesquisa de literatura científica nas bases de dados eletrônicas Scielo, Lilacs, BVS-ENF e CINAHL. Resultados: No recorte temporal de 2007 a 2019, foram selecionados onze artigos que satisfizeram aos critérios de busca. Os custos relacionados ao CME estão associados a diversos fatores, dentre eles: carga horária extensa de mão de obra especializada, tipos de processamentos e embalagens, reprocessamento de materiais estéreis que não foram utilizados e a forma de abastecimento adotada pela instituição (processamentos terceirizados ou produtos para saúde descartáveis). Conclusão: Os custos inerentes ao CME devem ser analisados de forma individualizada, respeitando a rotina e especificidade de cada centro de esterilização, para que ocorra otimização dos recursos e serviços sem abdicar da segurança dos processamentos.
\end{abstract}

Palavras-chave: Esterilização; Custos hospitalares; Centro de esterilização; Custos e análise de custo.

\begin{abstract}
Objective: to identify, through the literature, the costs related to the CME and propose ways to optimize such expenses within the scope of health institutions today. Method: Study of integrative review, through research of scientific literature in the electronic databases Scielo, Lilacs, BVS-ENF and CINAHL. Results: In the time frame from 2007 to 2019, eleven articles were selected that met the search criteria. Costs related to CME are associated with several factors, among them: extensive workload of specialized labor, types of processing and packaging, reprocessing of unused sterile materials and the form of supply adopted by the institution (outsourced processing or products disposable health
\end{abstract}


products). Conclusion: The costs inherent to the CME must be analyzed individually, respecting the routine and specificity of each sterilization center, so that resources and services can be optimized without sacrificing the security of processing.

Keywords: Sterilization; Hospital costs; Sterilization center; Costs and cost analysis.

\section{Resumen}

Objetivo: identificar, a través de la literatura, los costos relacionados con el CME y proponer formas de optimizar dichos gastos en el ámbito de las instituciones de salud en la actualidad. Método: Estudio de revisión integradora, mediante la búsqueda de literatura científica en las bases de datos electrónicas Scielo, Lilacs, BVS-ENF y CINAHL. Resultados: En el período de 2007 a 2019, se seleccionaron once artículos que cumplieron con los criterios de búsqueda. Los costos relacionados con la CME están asociados a varios factores, entre ellos: carga de trabajo extensa de mano de obra especializada, tipos de procesamiento y empaque, reprocesamiento de materiales estériles no utilizados y la forma de suministro adoptada por la institución (procesamiento subcontratado o productos desechables de salud). Conclusión: Los costos inherentes al CME deben analizarse de manera individual, respetando la rutina y la especificidad de cada centro de esterilización, de manera que se puedan optimizar recursos y servicios sin sacrificar la seguridad del procesamiento.

Palabras clave: Esterilización; Costos de hospital; Centro de esterilización; Costos y análisis de costo.

\section{Introdução}

Hospitais são instituições que prestam assistência em saúde e englobam as atividades de um vasto corpo profissional, com o objetivo de proporcionar serviços adequados, de alta qualidade e seguros a todos. O aumento da demanda em tais instituições, associado à evolução tecnológica colaboraram para uma significativa divergência entre os recursos financeiros disponíveis e os recursos necessários para acompanhar este avanço, fazendo-se necessária a gestão hospitalar (Cardoso, Souza, Reis \& Palha, 2020; Souza \& Cunha, 2020). Logo, o gerenciamento de custos é uma ferramenta essencial, visto que por meio deste controle será possível perceber gastos evitáveis e redirecionar recursos com vistas ao cumprimento dos objetivos supracitados (Pereira, Pascoal, Rolim, Ferreira \& Silva, 2020).

Nesse contexto, o Centro de Material e Esterilização (CME) é a unidade que concretiza os processamentos dos Produtos Para Saúde (PPS) que são materiais/produtos odonto-medico-hospitalares utilizados nos serviços das instituições (Oliveira \& Mati, 2017). É no CME que são realizados a limpeza, preparo, desinfecção ou esterilização, armazenamento e fornecimento dos materiais aos demais setores do hospital, sendo, desta forma, uma unidade de base para que todas as demais desempenhem seus trabalhos de forma segura (Gonçalves et al., 2020).

A desinfecção consiste em destruir e eliminar quase todos os microrganismos, com exceção dos endósporos bacterianos. Já a esterilização é a destruição total de todos os microrganismos, incluindo os esporos. Ambos os processamentos podem ser realizados por meios físicos ou químicos. Os tipos de esterilização são também classificados em Esterilização à Baixa Temperatura e à Alta Temperatura, sendo utilizados de acordo com a indicação de cada produto para saúde que será esterilizado, em relação à tolerância à temperatura (Paula, Silva, Vedovato \& Boaventura, 2015).

Como o setor responsável pelos processamentos de PPS que são utilizados diariamente com os pacientes, seja em cirurgias, curativos e em tantas outras atividades, o CME é um protagonista no combate à ocorrência de Infecções Relacionadas à Assistência em Saúde (IRAS), visto que, a qualidade dos serviços desenvolvidos neste setor reflete em todos os demais do hospital e na manutenção da saúde dos indivíduos que são assistidos (Miranda, Pinheiro \& Silva, 2019; Gonçalves et al., 2020; Vasconcelos et al., 2017).

A pandemia do novo coronavírus, declarada no ano de 2020, é um marco histórico que, dentre outras questões, evidencia a crucial importância dos processamentos dos materiais hospitalares, quebrando a cadeia de transmissão e visando a segurança de todos os indivíduos que receberem a assistência em saúde e, também, dos profissionais que atuem realizando-a (Silva, Loureiro, Silva \& Novaes, 2020). 
Dessa forma, o CME configura-se como um importante setor que necessita de recursos consideráveis direcionados aos equipamentos, insumos e mão de obra qualificada inerentes aos processamentos realizados (Pereira et al., 2020). Portanto, este estudo mostra-se relevante por evidenciar o que a literatura aponta a respeito das principais formas de custos relacionados ao CME e meios de controlar os gastos, mantendo a qualidade dos processamentos e a segurança da assistência em saúde desempenhada nas instituições, abordando, então, a importância do gerenciamento voltado para a ótica econômico-financeira, sem que ocorram danos aos serviços e mantendo o protagonismo de combate às IRAS.

O Enfermeiro é o gestor do CME, devendo atuar com uma visão holística do setor e operar como uma barreira para a ocorrência de falhas e como um amplificador para o sucesso dos serviços realizados (Alvim, Ramos \& Durão, 2019). Por fim, é nesse panorama complexo que torna-se fundamental ao enfermeiro conhecer os conceitos e custos das aquisições necessárias para uma assistência em saúde eficaz e segura (Cavalcante \& Barros, 2020), salientando que este estudo justifica-se por evidenciar as informações relacionadas aos custos no CME publicadas em bases de dados, de modo a contribuir no papel do enfermeiro em controlar, alocar ou eliminar gastos neste setor, com intuito de otimizá-los, tendo os custos relacionados ao CME como objeto de pesquisa.

Portanto, esta investigação foi realizada a fim de responder à questão norteadora da pesquisa: "O que corrobora, segundo a literatura, para a elevação dos custos relacionados às atividades e serviços do Centro de Material e Esterilização (CME) para a instituição? E como podem ser otimizados tais gastos?”. E tem como objetivo: identificar, através da literatura, os custos relacionados ao CME e propor formas de otimizar tais gastos no âmbito das instituições de saúde.

\section{Metodologia}

Este estudo trata-se de uma revisão literária integrativa, fruto da pesquisa de artigos publicados em bases de dados, de cunhos quantitativo e qualitativo, analisando e descrevendo os aspectos inerentes aos serviços do CME que representam importantes formas de custos neste setor, de modo a apresentar os fatores que levam aos gastos e valores onerados. Com o foco de elucidar o conhecimento a respeito de determinado conteúdo e aprofundá-lo, a revisão integrativa tem como estratégia reunir, avaliar e sintetizar os resultados encontrados nos mesmos, respeitando os diferentes tipos de abordagens metodológicas e delineamento utilizados, contribuindo para o aprofundamento das evidências científicas e proporcionando melhorias nos serviços em saúde (Camargo et al., 2018; Silva, C. et al., 2020; Ludke \& Andre, 2013).

A realização do estudo foi planejada em seis etapas já pré-estabelecidas para caracterização do conhecimento acerca do assunto de interesse. Tais etapas foram: I - definição da temática e questão norteadora da pesquisa; II - busca dos artigos nas bases de dados; III - triagem feita a partir da leitura dos títulos e resumos dos artigos encontrados nas bases de dados; IV - leitura na íntegra dos estudos pré-selecionados na etapa anterior para coleta de informações pertinentes ao estudo, bem como classificação do nível de evidência de cada um; V - fechamento da amostra final e explanação dos resultados encontrados nos artigos selecionados e VI - apresentação da Revisão Integrativa (Souza, Silva \& Carvalho, 2010).

Os critérios de inclusão estabelecidos foram: artigos científicos completos e disponíveis na íntegra, gratuitamente, nos idiomas português, inglês e espanhol, que respondam à pergunta norteadora desta revisão, publicados entre janeiro de 2007 até dezembro de 2019, com metodologia bem delimitada e que apresentem resultados pertinentes ao tema central desta revisão. E os critérios de exclusão foram: os artigos repetidos nas bases de dados (cada estudo foi aceito apenas uma vez, caso satisfizessem aos demais critérios), editoriais, cartas ao editor, teses, monografias, dissertações, entrevistas, artigos com fragilidade nos métodos ou desconexão entre objetivos e resultados e estudos que não se enquadrem ao tema central da revisão, não respondendo à questão norteadora. 
As Bases de Dados selecionadas para realização das buscas foram: Biblioteca Virtual em Saúde - Enfermagem (BVSENF), Literatura Latino-Americana e do Caribe em Ciências da Saúde (LILACS), Scientific Electronic Library Online (SciELO) e Cumulative Index to Nursing and Allied Health Literature (CINAHL).

As buscas foram realizadas em dois momentos: o primeiro foi feito entre os meses de agosto e outubro de 2020, utilizando o Descritor em Saúde (DeCS) "Esterilização", associado ao termo alternativo deste descritor (DeCS) "Centro de Esterilização" e à palavra-chave "Custos", por meio do operador boleando "AND", nos três idiomas da pesquisa: Esterilização AND Centro de esterilização AND Custos; Sterilization AND Sterilization center AND Costs; Esterilización AND Centro de esterilización AND Costos.

O segundo momento foi realizado nos meses de dezembro de 2020 e janeiro de 2021, com os Descritores em Saúde (DeCS) "Esterilização" e "Controle de Custos" associados ao termo alternativo do descritor Esterilização (DeCS) "Centro de Esterilização", por meio do operador boleando "AND”, nos três idiomas determinados na pesquisa: Esterilização AND controle de custos AND centro de esterilização; Sterilization AND Cost Control AND sterilization center; Esterilización AND Control de Costos AND centro de esterilización.

Além disso, foram realizadas nos dois momentos, buscas complementares com os descritores, termo alternativo e palavra-chave agrupados dois a dois, nos três idiomas escolhidos nesta pesquisa com vistas ao aumento dos artigos a respeito do tema.

Por fim, os artigos passaram pela classificação do nível de evidência, segundo o método de Melnyk e Fineout-Overholt que propõe sete níveis de evidência (Pompeo, Rossi \& Galvão, 2009), expostos na Figura 1.

Figura 1 - Níveis de Evidência Científica, por Melnyk e Fineout-Overholt. Brasil, 2021.

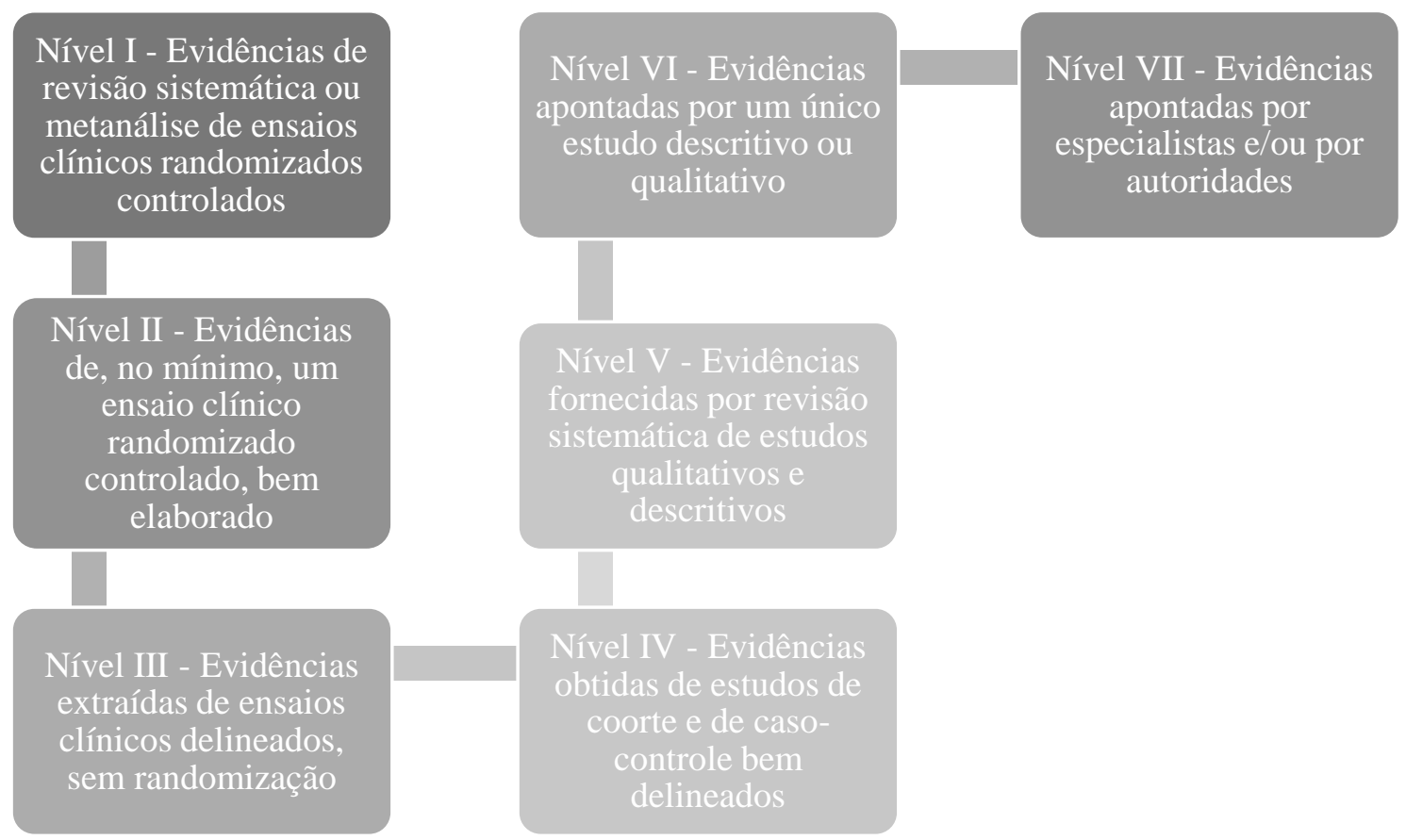

Fonte: Pompeo, Rossi e Galvão (2009).

Melnyk e Fineout-Overholt abordam sete níveis de evidência científica para os estudos de acordo com a metodologia de cada um e forma que o estudo é concretizado. Como exposto na Figura 1, o nível VI contempla as evidências dos estudos únicos de caráter descritivo ou qualitativo, encaixando-se, portanto todos os artigos da amostra final desta Revisão Integrativa (Pompeo, Rossi \& Galvão, 2009). 


\section{Resultados}

A coleta de dados possibilitou encontrar diversos artigos e as buscas realizadas com os descritores agrupados dois a dois ampliaram significativamente o número de estudos encontrados, no entanto, os temas abordados pela grande parte deles não é o assunto desta revisão, como esterilização feminina e masculina e estudos cirúrgicos, além de expressiva quantidade de artigos fora do recorte temporal definido neste estudo, justificando a disparidade entre a alta quantidade de artigos encontrados e o número discreto de selecionados, exposta nas Figuras 2 e 3.

Após a pré-seleção, os artigos foram lidos na íntegra e avaliado rigorosamente para compor a amostra final de onze artigos que foram apresentados na Tabela 1, com a identificação e título do artigo, ano e idiomas de publicação, objetivos, as bases de dados onde foram encontrados, periódico, tipo de estudo, local da pesquisa e nível de evidência científica que foi classificado pela proposta de Melnyk e Fineout-Overholt. Considerando que os estudos possuem caráter descritivo e/ou contemplam, cada estudo, apenas um local de pesquisa, adequam-se ao nível VI de evidência (Pompeo, Rossi \& Galvão, 2009).

Figura 2 - Fluxograma de seleção dos artigos pela primeira busca nas bases de dados pesquisadas. Brasil, 2021.

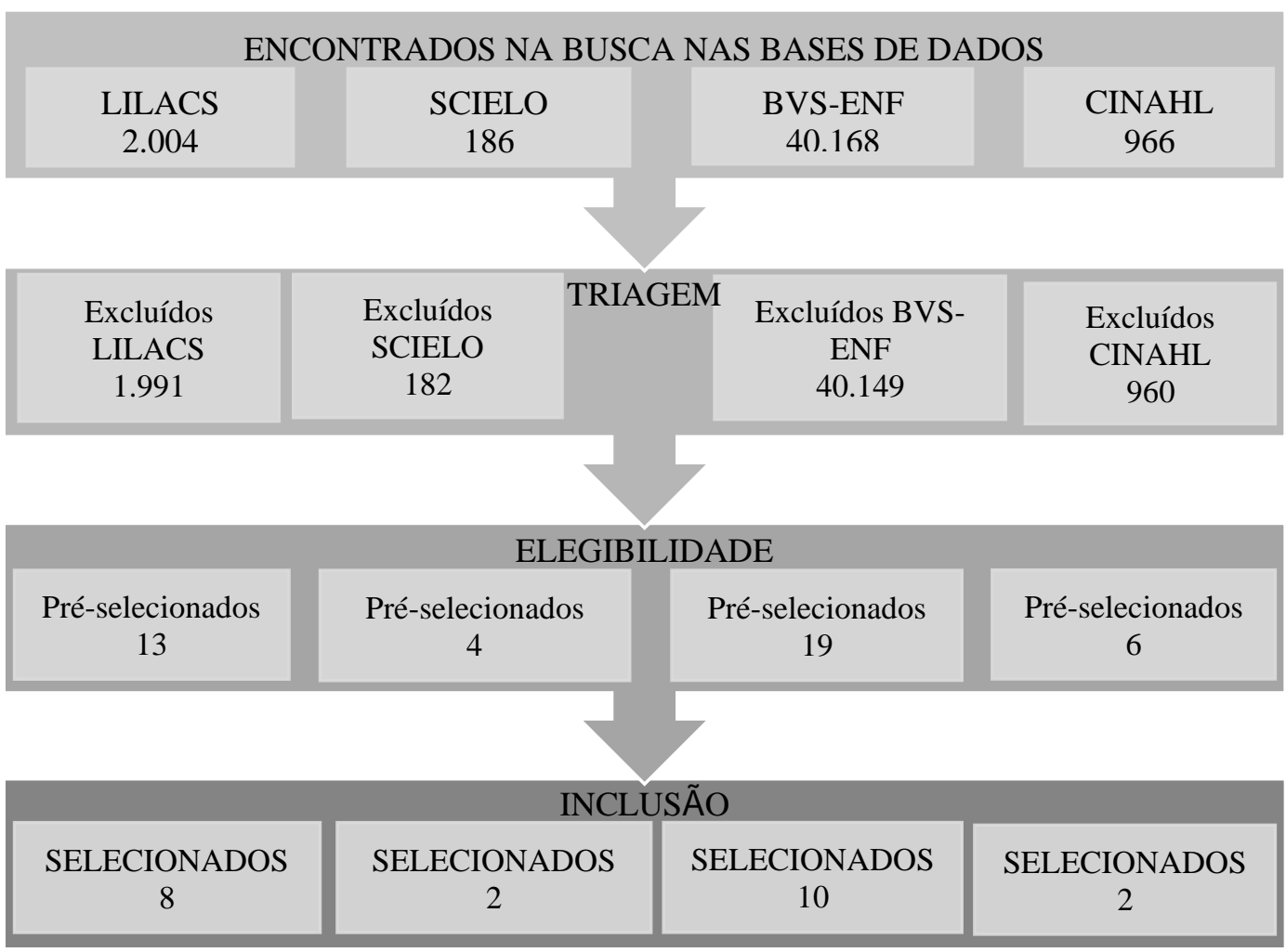

Fonte: Autores (2021). 
Figura 3 - Fluxograma de seleção dos artigos pela segunda busca nas bases de dados pesquisadas. Brasil, 2021.

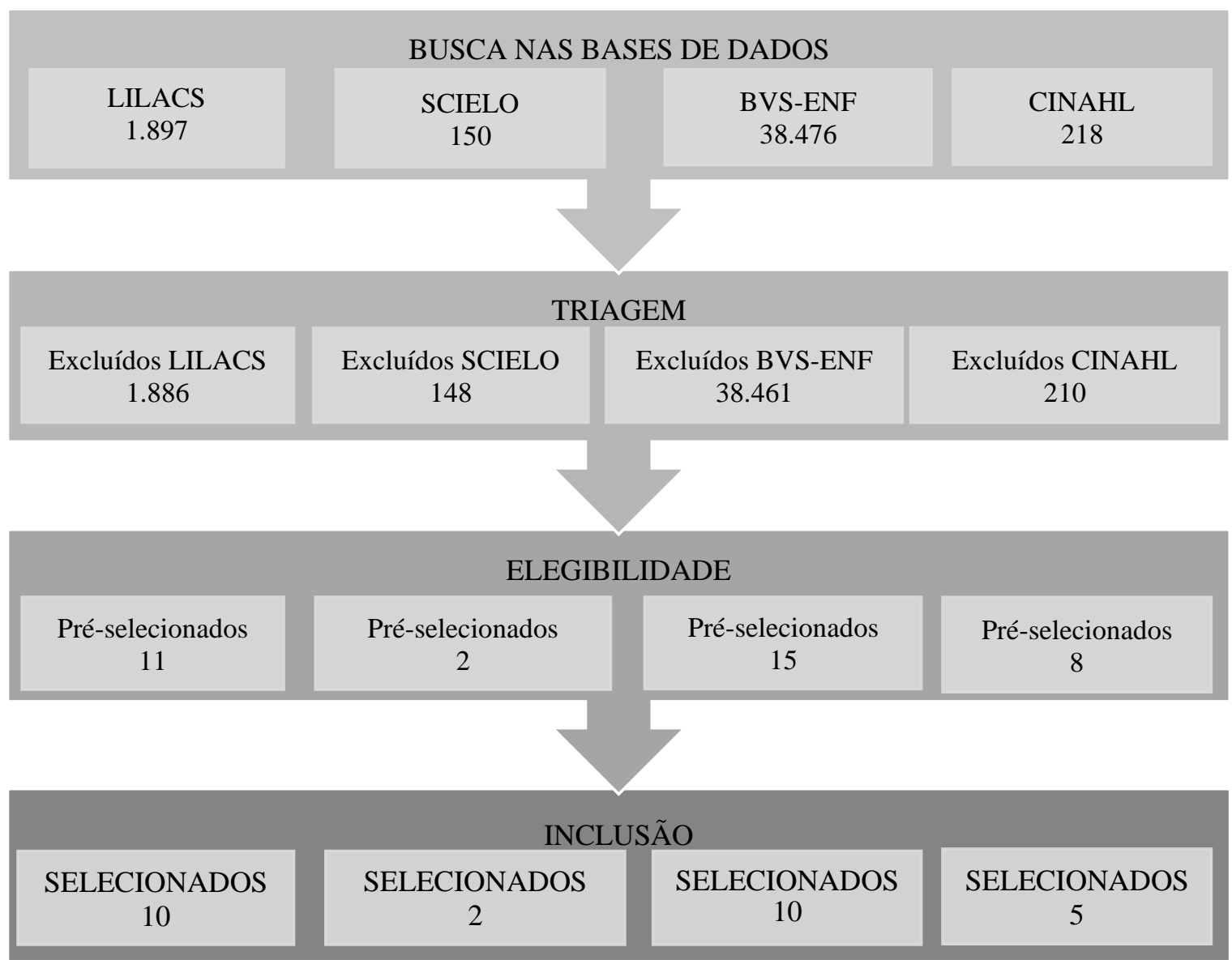

Fonte: Autores (2021).

Nas Figuras 2 e 3, observa-se as altas quantidades de artigos achados em cada base, no entanto, são apontados também números discretos de selecionados, confirmando o fato de escassez de estudos direcionados para a ótica econômico-financeira dos serviços do CME. Ou seja, muitos estudos abordam outros aspectos do centro de esterilização, outros temas ou não encaixam-se aos demais critérios de inclusão deste estudo, sendo excluídos nas etapas “Triagem” e "Elegibilidade” apontadas nestas figuras.

Os dois momentos de buscas em bases de dados permitiram alcançar a amostra final de onze artigos e, é válido destacar que os estudos que se repetiram nas bases de dados, foram contabilizados apenas uma vez. A base Biblioteca Virtual em Saúde - Enfermagem (BVS-ENF) tem destaque nesta amostra, pois dos onze artigos selecionados, dez são encontrados nesta base, constando apenas um artigo que não foi achado nesta, mas sim na base Cumulative Index to Nursing and Allied Health Literature (CINAHL).

O segundo momento de busca não acrescentou estudos na amostra final, pois os artigos novos pré-selecionados analisados na etapa de triagem não se adequaram aos critérios necessários para serem incluídos nesta revisão e os estudos selecionados foram os mesmos que o primeiro momento de busca já havia apontado.

Abaixo consta o Quadro 1, contendo as principais informações dos artigos da amostra final desta Revisão Integrativa. 
Quadro 1 - Detalhamento dos artigos selecionados na amostra final da revisão. Brasil, 2021.

\begin{tabular}{|c|c|c|c|c|}
\hline $\begin{array}{c}\text { Identificação/Título do } \\
\text { Artigo } \\
\text { Ano e idioma de publicação }\end{array}$ & Objetivos & $\begin{array}{l}\text { Bases de dados e } \\
\text { Periódico }\end{array}$ & $\begin{array}{c}\text { Tipo de estudo } \\
\text { Local de Pesquisa }\end{array}$ & $\begin{array}{l}\text { Nível de } \\
\text { Evidência }\end{array}$ \\
\hline $\begin{array}{l}\text { A01 - SURGERY } \\
\text { CANCELLING AT A } \\
\text { TEACHING HOSPITAL: } \\
\text { IMPLICATIONS FOR COST } \\
\text { MANAGEMENT } \\
2007 \text { - Inglês, Português e } \\
\text { Espanhol }\end{array}$ & $\begin{array}{l}\text { Identificar e analisar a } \\
\text { distribuição do custo } \\
\text { direto, relativo a } \\
\text { recursos humanos, } \\
\text { insumos consumidos } \\
\text { (materiais de consumo } \\
\text { e reprocessados) e } \\
\text { medicamentos, gerado } \\
\text { pelo cancelamento de } \\
\text { cirurgias eletivas na } \\
\text { Unidade de Centro } \\
\text { Cirúrgico de um } \\
\text { hospital de ensino }\end{array}$ & $\begin{array}{l}\text { Scielo, Lilacs e } \\
\text { BVS-ENF } \\
\text { Revista Latino- } \\
\text { americana de } \\
\text { Enfermagem }\end{array}$ & $\begin{array}{l}\text { Estudo } \\
\text { exploratório } \\
\text { descritivo, } \\
\text { realizado no } \\
\text { Centro Cirúrgico } \\
\text { (CC) de um } \\
\text { hospital de ensino, } \\
\text { em uma cidade do } \\
\text { interior do Estado } \\
\text { de São Paulo - BR }\end{array}$ & $\begin{array}{l}\text { VI (Pompeo, } \\
\text { Rossi \& } \\
\text { Galvão, 2009) }\end{array}$ \\
\hline $\begin{array}{l}\text { A02 - Gerenciamento de } \\
\text { custos: aplicação do método } \\
\text { de custeio baseado em } \\
\text { atividades (ABC) em CME } \\
2010 \text { - Português e Inglês }\end{array}$ & $\begin{array}{l}\text { Identificar o custo do } \\
\text { processamento de } \\
\text { desinfecção e } \\
\text { esterilização dos } \\
\text { artigos médico } \\
\text { hospitalares. }\end{array}$ & 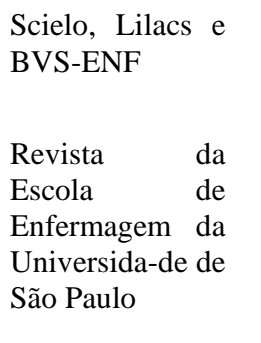 & $\begin{array}{l}\text { Estudo exploratório } \\
\text { descritivo, na } \\
\text { modalidade estudo } \\
\text { de raso, } \\
\text { desenvolvido em um } \\
\text { CME de um hospital } \\
\text { de ensino, na região } \\
\text { noroeste do Estado } \\
\text { de São Paulo - BR }\end{array}$ & $\begin{array}{l}\text { VI (Pompeo, } \\
\text { Rossi \& } \\
\text { Galvão, 2009) }\end{array}$ \\
\hline $\begin{array}{l}\text { A03 - Using activities-based } \\
\text { costing in a sterile processing } \\
\text { department as a management } \\
\text { tool } \\
2015 \text { - Inglês e Português }\end{array}$ & $\begin{array}{l}\text { Avaliar a aplicação do } \\
\text { sistema de custeio } \\
\text { baseado em } \\
\text { atividades, no centro } \\
\text { de material e } \\
\text { esterilização de uma } \\
\text { instituição hospitalar } \\
\text { pública, visando uma } \\
\text { prática gerencial } \\
\text { baseada em evidências } \\
\text { e seu consequente } \\
\text { apoio ao processo de } \\
\text { tomada de decisão }\end{array}$ & $\begin{array}{l}\text { Lilacs, BVS- } \\
\text { ENF e CINAHL } \\
\text { Revista Eletrônica } \\
\text { de Enfermagem }\end{array}$ & $\begin{array}{l}\text { Pesquisa aplicada, } \\
\text { descritiva, } \\
\text { exploratória, na } \\
\text { modalidade estudo de } \\
\text { caso, feita no CME de } \\
\text { um hospital público, } \\
\text { estadual, de ensino, } \\
\text { localizado no interior } \\
\text { do Estado de São } \\
\text { Paulo - BR }\end{array}$ & $\begin{array}{l}\text { VI (Pompeo, } \\
\text { Rossi \& } \\
\text { Galvão, 2009) }\end{array}$ \\
\hline $\begin{array}{l}\text { A04 - Instrumentais nas } \\
\text { caixas cirúrgicas: Avaliação } \\
\text { de custo } \\
2015 \text { - Português }\end{array}$ & $\begin{array}{l}\text { Avaliar o número de } \\
\text { instrumentais das } \\
\text { caixas cirúrgicas que } \\
\text { não são utilizados } \\
\text { durante as cirurgias e } \\
\text { estimar os custos com } \\
\text { o processo de } \\
\text { esterilização desses } \\
\text { nesta instituição }\end{array}$ & $\begin{array}{l}\text { Lilacs e BVS- } \\
\text { ENF } \\
\text { Revista } \\
\text { SOBECC }\end{array}$ & $\begin{array}{l}\text { Estudo quantitativo, } \\
\text { descritivo, de campo e } \\
\text { observacional, } \\
\text { realizado no CC de } \\
\text { um hospital de } \\
\text { manutenção privada, } \\
\text { em uma cidade do } \\
\text { interior do Estado de } \\
\text { São Paulo }\end{array}$ & $\begin{array}{l}\text { VI (Pompeo, } \\
\text { Rossi \& } \\
\text { Galvão, 2009) }\end{array}$ \\
\hline $\begin{array}{l}\text { A05 - Mapeamento do } \\
\text { processo de reprocessamento } \\
\text { de campos cirúrgicos de } \\
\text { tecido de algodão } \\
2015 \text { - Português }\end{array}$ & $\begin{array}{l}\text { Mapear as etapas e } \\
\text { atividades relativas ao } \\
\text { processo de repro- } \\
\text { cessamento de campos } \\
\text { de tecido de algodão } \\
\text { duplos e simples } \\
\text { integrantes do pacote } \\
\text { de LAP cirúrgico }\end{array}$ & $\begin{array}{l}\text { Lilacs, BVS- } \\
\text { ENF e CINAHL } \\
\text { Revista } \\
\text { SOBECC }\end{array}$ & $\begin{array}{l}\text { Estudo de caso único, } \\
\text { exploratório, } \\
\text { descritivo, } \\
\text { desenvolvido em um } \\
\text { hospital de ensino da } \\
\text { Pontifícia } \\
\text { Universidade de São } \\
\text { Paulo, situado na } \\
\text { cidade de Sorocaba }\end{array}$ & $\begin{array}{l}\text { VI (Pompeo, } \\
\text { Rossi \& } \\
\text { Galvão, 2009) }\end{array}$ \\
\hline $\begin{array}{l}\text { A06 - Uso do sistema de } \\
\text { custo baseado em atividades }\end{array}$ & $\begin{array}{l}\text { Comparar os custos } \\
\text { diretos envolvidos nas } \\
\text { tecnologias de }\end{array}$ & $\begin{array}{ll}\text { BVS-ENF } & \\
\text { Revista } & \text { de } \\
\text { Enfermagem } & \text { da }\end{array}$ & $\begin{array}{l}\text { Estudo qualitativo, } \\
\text { exploratório - } \\
\text { descritivo, }\end{array}$ & $\begin{array}{l}\text { VI (Pompeo, } \\
\text { Rossi \& } \\
\text { Galvão, 2009) }\end{array}$ \\
\hline
\end{tabular}




\begin{tabular}{|c|c|c|c|c|}
\hline $\begin{array}{l}\text { para gerenciar a esterilização } \\
\text { de materiais } \\
2017 \text { - Português }\end{array}$ & $\begin{array}{l}\text { Esterilização à Baixa } \\
\text { Temperatura (EBT) } \\
\text { utilizadas no CME de } \\
\text { um Hospital } \\
\text { Universitário, bem } \\
\text { como avaliar a relação } \\
\text { custo-benefício } \\
\text { envolvida no emprego } \\
\text { desta tecnologia }\end{array}$ & $\begin{array}{l}\text { Universida-de } \\
\text { Federal de } \\
\text { Pernambuco } \\
\text { (UFPE) on line }\end{array}$ & $\begin{array}{l}\text { observacional, } \\
\text { feito em um CME } \\
\text { de um Hospital } \\
\text { Universitário }\end{array}$ & \\
\hline $\begin{array}{l}\text { A07 - Assessment and control } \\
\text { of instruments utilized in } \\
\text { operating room during thoracic } \\
\text { surgeries } \\
2017 \text { - Inglês e Português }\end{array}$ & $\begin{array}{l}\text { Avaliar o número de } \\
\text { instrumentais } \\
\text { cirúrgicos utilizados e } \\
\text { não utilizados que } \\
\text { compõem as caixas } \\
\text { cirúrgicas das cirur- } \\
\text { gias torácicas }\end{array}$ & $\begin{array}{l}\text { LILACS e BVS- } \\
\text { ENF } \\
\text { Revista } \\
\text { SOBECC }\end{array}$ & $\begin{array}{l}\text { Estudo descritivo, } \\
\text { observacional, } \\
\text { transversal, com } \\
\text { abordagem } \\
\text { quantitativa, realizado } \\
\text { em um hospital } \\
\text { universitário da } \\
\text { cidade de Campinas } \\
\text { (SP) }\end{array}$ & $\begin{array}{l}\text { VI (Pompeo, } \\
\text { Rossi \& } \\
\text { Galvão, 2009) }\end{array}$ \\
\hline $\begin{array}{l}\text { A08 - CAUSAS DE } \\
\text { RETRABALHO DE } \\
\text { PRODUTOS PARA SAÚDE } \\
\text { NO CENTRO DE } \\
\text { MATERIAIS E } \\
\text { ESTERILIZAÇÃO } \\
2018 \text { - Português e Inglês }\end{array}$ & $\begin{array}{l}\text { Identificar as } \\
\text { principais causas de } \\
\text { retrabalho dos } \\
\text { produtos para saúde, } \\
\text { detectadas no CME }\end{array}$ & $\begin{array}{l}\text { LILACS, BVS- } \\
\text { ENF e CINAHL } \\
\text { Revista } \\
\text { SOBECC }\end{array}$ & $\begin{array}{l}\text { Trata-se de um estudo } \\
\text { descritivo, de } \\
\text { natureza quantitativa, } \\
\text { desenvolvido em um } \\
\text { CME de um hospital } \\
\text { geral particular de } \\
\text { Belo Horizonte, } \\
\text { Minas Gerais, Brasil }\end{array}$ & $\begin{array}{l}\text { VI (Pompeo, } \\
\text { Rossi \& } \\
\text { Galvão, 2009) }\end{array}$ \\
\hline $\begin{array}{l}\text { A09 - Comparação de custos } \\
\text { em diferentes processos de } \\
\text { abastecimento de materiais de } \\
\text { fisioterapia respiratória em um } \\
\text { hospital público de porte extra } \\
2018 \text { - Inglês e Português }\end{array}$ & $\begin{array}{l}\text { Comparar os custo de } \\
\text { diferentes processos } \\
\text { de abastecimento dos } \\
\text { materiais de terapia } \\
\text { respiratória em um } \\
\text { hospital geral, } \\
\text { público, e de alta } \\
\text { complexidade }\end{array}$ & $\begin{array}{l}\text { LILACS e BVS- } \\
\text { ENF } \\
\text { Revista Pesquisa } \\
\text { em Fisioterapia }\end{array}$ & $\begin{array}{l}\text { Estudo observacional, } \\
\text { com revisão } \\
\text { documental e análise } \\
\text { crítica, concretizado } \\
\text { em um hospital geral } \\
\text { e público da cidade de } \\
\text { São Paulo }\end{array}$ & $\begin{array}{l}\text { VI (Pompeo, } \\
\text { Rossi \& } \\
\text { Galvão, 2009) }\end{array}$ \\
\hline $\begin{array}{l}\text { A10 - ANÁLISE DE CUSTOS } \\
\text { DE EMBALAGENS PARA } \\
\text { ESTERILIZAÇÃO } \\
\text { UTILIZANDO CUSTEIO } \\
\text { BASEADO EM ATIVIDADES } \\
2016 \text { - Português }\end{array}$ & $\begin{array}{l}\text { Analisar o custo das } \\
\text { embalagens de um } \\
\text { centro de material } \\
\text { esterilizado utilizando } \\
\text { o método de Custeio } \\
\text { Baseado em } \\
\text { Atividades }\end{array}$ & $\begin{array}{l}\text { CINAHL } \\
\text { Revista de } \\
\text { Enfermagem } \\
\text { UFPE on line }\end{array}$ & $\begin{array}{l}\text { Estudo descritivo, } \\
\text { observacional, } \\
\text { realizado no CME e } \\
\text { na Lavanderia } \\
\text { Hospitalar de um } \\
\text { Hospital do } \\
\text { Universitário do deste brasileiro } \\
\text { Nordes }\end{array}$ & $\begin{array}{l}\text { VI (Pompeo, } \\
\text { Rossi \& } \\
\text { Galvão, 2009) }\end{array}$ \\
\hline $\begin{array}{l}\text { A11 - SISTEMÁTICA PARA } \\
\text { RACIONALIZAÇÃO DE } \\
\text { INSTRUMENTAIS DE } \\
\text { BANDEJAS CIRÚRGICAS }\end{array}$ & $\begin{array}{l}\text { Relatar a experiência } \\
\text { do desenvolvimento } \\
\text { de uma sistemática } \\
\text { para racionalização de } \\
\text { instrumentais em } \\
\text { bandejas cirúrgicas, } \\
\text { buscando reduzir o } \\
\text { volume de material } \\
\text { não utilizado no } \\
\text { procedimento a ser } \\
\text { limpo e esterilizado e } \\
\text { realocar os } \\
\text { instrumentais entre as } \\
\text { bandejas }\end{array}$ & $\begin{array}{l}\text { LILACS, BVS- } \\
\text { ENF e CINAHL } \\
\text { Revista } \\
\text { SOBECC }\end{array}$ & $\begin{array}{l}\text { Estudo qualitativo, } \\
\text { exploratório e } \\
\text { descritivo, conduzido } \\
\text { em um CME de um } \\
\text { hospital universitário } \\
\text { federal na cidade de } \\
\text { Porto Alegre, BR }\end{array}$ & $\begin{array}{l}\text { VI (Pompeo, } \\
\text { Rossi \& } \\
\text { Galvão, 2009) }\end{array}$ \\
\hline
\end{tabular}

Legenda: CME - Centro de Material e Esterilização; CC - Centro Cirúrgico; LAP cirúrgico - Pacote padrão com campos de tecido de algodão - seis duplos, um simples e um para embalagem (Tomé \& Lima, 2015). 
No Quadro 1, foram explanados os principais aspectos de cada artigo da amostra final desta revisão, sendo possível observar os locais de realização da investigação, bem como os tipos de estudos, ano de publicação, nível de evidência científica, objetivo, periódico e bases encontradas.

Os artigos da amostra final trouxeram apontamentos relevantes a respeito das formas de custos relacionados às atividades realizadas no CME e os principais resultados de cada estudo foram explanados no quadro 2.

Quadro 2 - Principais resultados encontrados nos artigos da amostra final. Brasil, 2021.

\begin{tabular}{|c|c|}
\hline Artigo & Principais resultados encontrados \\
\hline A01 & $\begin{array}{l}\text { Este trabalho evidenciou que, no período entre setembro e novembro de } 2004 \text {, foram cancelados } 58 \\
\text { procedimentos cirúrgicos que acarretaram gastos para a instituição hospitalar. Os itens, observados } \\
\text { neste estudo, que formam a lista dos gastos gerados pelos cancelamentos cirúrgicos são: recursos } \\
\text { humanos, materiais de consumo, materiais reprocessados e medicamentos. Tratando-se dos gastos } \\
\text { que são relacionados ao CME, diante destes cancelamentos cirúrgicos analisados, os custos foram } \\
\text { computados pelo processamento da rouparia (R } \$ 141,90) \text { e com os instrumentais previamente } \\
\text { embalados e processados ( } \$ \text { S9,32). }\end{array}$ \\
\hline A02 & $\begin{array}{l}\text { O CME investigado neste estudo faz parte de uma instituição hospitalar de ensino que realiza os } \\
\text { processamentos de Esterilização por vapor saturado sob pressão e Desinfecção Física ou Química. } \\
\text { Além disso, os produtos termossensíveis são encaminhados para outra instituição terceirizada para } \\
\text { serem esterilizados por Vapor a Baixa Temperatura de Formaldeído. Foi constatado que, no ano de } \\
2007 \text {, os valores unitários por carga/ciclo (em dólar) foi de: } 12,63 \text { - Desinfecção Física; } 9,95 \text { - } \\
\text { Desinfecção Química; } 255,28 \text { - Esterilização por Vapor a Baixa Temperatura de Formaldeído; e } \\
31,37 \text { - Esterilização por vapor saturado sob pressão. Nota-se que, neste caso, os custos com } \\
\text { Esterilização por Vapor a Baixa Temperatura de Formaldeído foram, significativamente, mais } \\
\text { elevados. Além disso, este estudo aponta que, por conta da extensa carga horária de trabalho, a mão } \\
\text { de obra representa um importante detentor de recursos do CME. }\end{array}$ \\
\hline A03 & $\begin{array}{l}\text { Este estudo permitiu mapear as etapas dos processamentos realizados (esterilização e desinfecção), } \\
\text { de modo a apontar que os custos estão relacionados com o tipo de processamento realizado, pois } \\
\text { cada um é constituído por etapas distintas que representam custos no valor total. Comparando, no } \\
\text { CME deste estudo, os custos da desinfecção e da esterilização, encontrou-se que o custo unitário } \\
\text { médio da desinfecção foi de } \mathrm{R} \$ 3,03 \text { e a esterilização } \mathrm{R} \$ 6,05 \text {, no ano de } 2012 \text {. É notável que a } \\
\text { esterilização é mais onerosa em relação à desinfecção e isto está relacionado ao objetivo e à } \\
\text { complexidade inerente ao processo de esterilização. }\end{array}$ \\
\hline A04 & $\begin{array}{l}\text { Esta pesquisa destacou que foram para as salas de operação } 934 \text { instrumentais, previamente } \\
\text { esterilizados, e que } 485 \text { destes não foram utilizados. Assim, a investigação concluiu que este CC } \\
\text { apresentou } 52 \% \text { de instrumentais abertos e não utilizados, logo, determinando que estes produtos } \\
\text { passarão novamente por todo o processo de esterilização, representando um gasto desnecessário (e } \\
\text { evitável) de instrumentais que não foram utilizados. }\end{array}$ \\
\hline A05 & $\begin{array}{l}\text { A partir do mapeamento de todas as etapas do processamento de campos cirúrgicos, duplos e } \\
\text { simples, de tecido de algodão que formam um pacote padronizado denominado LAP cirúrgico, } \\
\text { apesar deste artigo não explanar valores de custos, é abordado que o CME investigado neste estudo } \\
\text { realiza montagem e esterilização de } 40 \text { a } 60 \text { pacotes de LAP ao dia, o que aponta um tempo } \\
\text { significativo de trabalho de mão de obra especializada. Neste CME, o pacote padronizado (LAP) é } \\
\text { composto por seis campos cirúrgicos de tecido de algodão duplos, um simples e um para embalagem. }\end{array}$ \\
\hline A06 & $\begin{array}{l}\text { De modo a conhecer e comparar os custos exclusivamente relacionados ao processamento de } \\
\text { produtos hospitalares por meio da Esterilização a Baixa Temperatura, por meio das seguintes } \\
\text { tecnologias: Óxido de Etileno; Vapor a Baixa Temperatura de Formaldeído; e Peróxido de } \\
\text { Hidrogênio na forma de Plasma Gás. Foi constatado que são aplicados: } \mathrm{R} \$ 434,28 \text { por ciclo de } \\
\text { esterilização por Óxido de Etileno; } \mathrm{R} \$ 303,72 \text { por ciclo de esterilização por Vapor a Baixa } \\
\text { Temperatura de Formaldeído; e } \mathrm{R} \$ 485,32 \text { por ciclo de esterilização por Peróxido de Hidrogênio na } \\
\text { forma de Plasma Gás. Observou-se que a esterilização por Vapor a Baixa Temperatura de } \\
\text { Formaldeído foi considerada mais rentável para o CME desta investigação. }\end{array}$ \\
\hline
\end{tabular}




\begin{tabular}{|c|c|}
\hline A07 & $\begin{array}{l}\text { Analisando o quantitativo de instrumentais de caixas cirúrgicas, disponibilizado para cirurgias de } \\
\text { tórax, que foram ou não utilizados em ditos procedimentos, foi observado que, no total de } 30 \\
\text { cirurgias torácicas analisadas, em } 2015 \text {, foram contabilizados } 3.333 \text { instrumentais, dos quais } 516 \\
\text { tiveram suas embalagens abertas, mas os artigos não foram usados, configurando o mesmo tipo de } \\
\text { gasto desnecessário mencionado no estudo A04. }\end{array}$ \\
\hline A08 & $\begin{array}{l}\text { A fim de identificar as principais causas de reprocessamento de produtos para saúde em um CME, } \\
\text { esta investigação permitiu perceber que, em } 2016 \text {, dos } 80.568 \text { produtos, } 605 \text { foram reprocessados. } \\
\text { As principais causas de retrabalho apontadas neste estudo foram: datas de validade expiradas e } \\
\text { resíduo orgânico pós-esterilização ( } 74,2 \% \text { e } 13 \% \text {, respectivamente). Tal fato implicará em custos } \\
\text { evitáveis para o CME por conta da nova realização do processamento, sem ter sido utilizado o } \\
\text { produto. Essa forma de custo assemelha-se à forma mencionada nos estudos A04 e A07. }\end{array}$ \\
\hline A09 & $\begin{array}{l}\text { Comparando os custos de três diferentes formas de abastecimento (Materiais processados em CME } \\
\text { da própria instituição; Materiais processados em CME contratada - terceirizada; e materiais } \\
\text { descartáveis) de materiais de terapia respiratória, em um hospital geral público, foi concluído que o } \\
\text { abastecimento deste Hospital feito por produtos descartáveis é o mais dispendioso, enquanto a } \\
\text { aquisição e processamento em CME próprio da instituição representa a forma com menores custos. } \\
\text { O abastecimento pelo CME externo é mais caro em relação ao processamento em CME próprio, mas } \\
\text { é mais rentável em relação à aquisição de produtos descartáveis. }\end{array}$ \\
\hline A10 & $\begin{array}{l}\text { Com vista à comparação de custos das embalagens de tecido de algodão e papel grau cirúrgico } \\
\text { utilizadas em produtos que serão esterilizados por Vapor Saturado sob Pressão (alta temperatura), } \\
\text { esta investigação apresentou que o empacotamento com a embalagem dupla de papel grau cirúrgico, } \\
\text { feita com a utilização dos tamanhos } 20 \mathrm{~cm} \times 40 \mathrm{~cm} \text { e } 20 \mathrm{~cm} \times 50 \mathrm{~cm} \text {, custou } \mathrm{R} \$ 1,45 \text {, sendo: } \mathrm{R} \$ 0,23 \mathrm{da} \\
\text { mão de obra (de acordo com o tempo aplicado para a montagem com esta embalagem); } \mathrm{R} \$ 0,02 \mathrm{da} \\
\text { fita teste; e } \mathrm{R} \$ 1,20 \text { do papel. A embalagem dupla do mesmo material, feita com os tamanhos } 30 \mathrm{~cm} \\
\text { x } 30 \mathrm{~cm} \text { e } 30 \mathrm{~cm} \times 40 \mathrm{~cm} \text { custou } \mathrm{R} \$ 1,32 \text {, sendo: } \mathrm{R} \$ 0,30 \text { da mão de obra; } \mathrm{R} \$ 0,02 \text { da fita teste; e } \mathrm{R} \$ 1,00 \\
\text { do papel. O empacotamento feito com os campos cirúrgicos de tecido de algodão teve seu valor } \\
\text { encontrado levando em consideração cada material utilizado para empacotar os produtos com dois } \\
\text { campos de algodão (campo duplo), fita crepe para fechar o pacote, a fita teste (zebrada) e, ainda, } \\
\text { tudo o que é gasto com o reprocessamento do próprio campo (água, mão de obra, sabão, entre } \\
\text { outros). Os empacotamentos feitos com os campos de maior tamanho utilizado na instituição, } 1,40 \mathrm{~m} \\
\text { x } 1,40 \mathrm{~m} \text {, custaram, cada um, } \mathrm{R} \$ 27,30 \text {; e os de menor tamanho, } 40 \mathrm{~cm} \times 40 \mathrm{~cm} \text {, custaram, cada um, } \\
\mathrm{R} \$ 18,90 \text {. }\end{array}$ \\
\hline A11 & $\begin{array}{l}\text { Abordando o desenvolvimento da racionalização de instrumentais cirúrgicos dispostos em bandejas } \\
\text { cirúrgicas, com o objetivo de diminuir o quantitativo de materiais não utilizados que passariam } \\
\text { novamente pelo processamento de esterilização, a pesquisa mencionada evidenciou que após a } \\
\text { análise dos materiais cirúrgicos, de um total de } 9.561 \text { instrumentais da instituição em questão, } 841 \\
\text { instrumentais voltaram para o arsenal do CME, com vista a uma futura utilização, caso necessário, } \\
\text { em uma nova caixa cirúrgica e outras } 498 \text { peças foram definitivamente desativadas, porque os } \\
\text { profissionais concluíram que estes instrumentais não seriam mais utilizados, uma vez que as técnicas } \\
\text { cirúrgicas estão em constante evolução e, consequentemente, utilização de novo material para a } \\
\text { realização das mesmas. Ademais, no desenvolvimento deste estudo, foi possível realocar } \\
\text { instrumentais e utilizar alguns que estavam no arsenal do CME para montar novas caixas cirúrgicas, } \\
\text { o que fez com que a instituição economizasse } \mathrm{R} \$ 14.000,00 \text { que seriam empregados na aquisição de } \\
\text { novas bandejas para cirurgias urológicas. }\end{array}$ \\
\hline
\end{tabular}

Fonte: Autores (2021).

Neste Quadro 2, pode-se analisar os principais resultados que cada estudo aponta como fatores relacionados aos custos inerentes ao CME investigado.

\section{Discussão}

Como explanado no Quadro 2, este estudo possibilitou o conhecimento de algumas atividades que contribuem para os custos relacionados ao $\mathrm{CME}$ e, por vezes, podem ocorrer fatores que colaboram para aplicações inadequadas de recursos, 
configurando-se como gastos evitáveis. Diante dessas formas de gastos, o gerenciamento das atividades do setor é crucial para esclarecer quais são as origens de gastos, o porquê dos mesmos e o que pode ser evitado e/ou redirecionado (Pereira et al., 2020).

Nesse contexto, é apresentado no A01 que 58 procedimentos cirúrgicos foram cancelados e ocasionaram gastos evitáveis ao CME da instituição estudada. Tais gastos foram oriundos do processamento da rouparia e com os instrumentais previamente embalados e processados. Observa-se, na prática cotidiana, que os cancelamentos cirúrgicos causam desperdícios em diversos sentidos: além de implicarem consequências aos pacientes e familiares, os profissionais de saúde perdem tempo de trabalho e a instituição hospitalar arca com os custos inerentes a isso. Segundo Santos e Bocchi (2017), o custo médio é de $\mathrm{R} \$ 29,54$ por paciente, referente aos materiais reprocessados, medicamentos e insumos, por cirurgia cancelada. Este mesmo estudo ainda evidencia que devem ser analisados os valores aplicados indiretamente, com preparo e ocupação da sala operatória, tempo dos profissionais envolvidos no procedimento cirúrgico e, ainda, a impossibilidade de ganho com a cirurgia que foi cancelada.

Pode-se afirmar que o adequado gerenciamento do planejamento cirúrgico funciona como elemento sanativo para tais eventualidades, considerando que os principais motivos de cancelamentos são relacionados a condições clínicas desfavoráveis dos pacientes desfavoráveis, o não comparecimento do paciente e a falta de leitos em UTIs e de internação (Botazini \& Carvalho, 2017).

Uma boa comunicação com as equipes de outros setores e com os pacientes são a base para tal gestão, de modo que as vagas sejam previamente confirmadas e os pacientes sejam esclarecidos sobre a necessidade do procedimento cirúrgico. Em contrapartida, é de extrema relevância ressaltar que, no dia a dia de funcionamento hospitalar, ocorrem emergências que podem levar ao cancelamento de uma cirurgia eletiva ou até a ocupação de um leito em UTI, sendo, portanto, motivos nobres que retiram totalmente a importância do foco nos custos por cancelamentos, no momento ocorrido (Botazini \& Carvalho, 2017; Pinheiro et al., 2017).

A partir dos resultados dos estudos A02, A03 e A06, destaca-se o fato de que cada tipo de processamento tem seu custo, de acordo com as atividades inerentes às etapas deles, sendo, portanto, o tipo de processamento desenvolvido no CME um ponto crucial a ser avaliado para que se tenha acesso às informações relacionadas aos custos.

Como confirmado nos resultados do A02 e A03, o processamento de desinfecção é consideravelmente mais barato em relação ao de esterilização, sendo justificado pelas etapas inerentes a cada processo, a utilização das tecnologias necessárias a cada um e mão de obra necessária. Porém, é necessário enfatizar que não se pode comparar os custos relacionados ao processo de esterilização com os inerentes ao processo de desinfecção, pois estes métodos têm propósitos distintos e atividades distintas compondo o processo de cada um. E, ainda, nenhuma instituição de saúde pode renunciar ao processo mais caro (esterilização), pois este é quem garante a morte de todos os microrganismos dos artigos de saúde (Morais, Serrano, Santos, Oliveira \& Melo, 2018; Alcântara et al., 2019).

No contexto hospitalar, faz-se necessário que o CME apresente formas de processamentos que possam adequar-se aos tipos de materiais que são utilizados na rotina assistencial. Neste sentido, é essencial que seja analisado, de maneira personalizada, as melhores formas de desinfecção, esterilização à baixa temperatura e à alta temperatura que serão adotadas em cada CME, com vistas a contemplar todos os produtos utilizados na instituição, respeitando o adequado processamento a cada um (Graziano et al., 2017).

Assim sendo, para que sejam analisados os processamentos, estes devem ser comparados entre si para a rotina do CME que deseja adotar um novo gerenciamento de custos, de forma que: as formas de desinfecção devem ser comparadas entre si, assim como as formas de esterilização à baixa temperatura; e as formas de esterilização à alta temperatura, visto que os valores são diferentes, mas todos esses processamentos são necessários. Logo, o gestor deve analisar qual a melhor forma de desinfecção para o seu CME, assim como a melhor forma de esterilização à baixa temperatura e à alta temperatura para sua rotina, de acordo 
com os produtos, quantidade e necessidade de abastecimento da instituição, não abdicando de nenhum tipo de processamento, pois estes estão diretamente relacionados à qualidade e à segurança da assistência em saúde (Graziano et al., 2017).

Outra forma relevante de custos no CME é a carga horária de trabalho extensa da mão de obra especializada, como foi mencionado nos artigos A02 e A05. O dimensionamento de pessoal do CME deve ser realizado pelo Enfermeiro, em posse dos conhecimentos sobre: as atividades atribuídas aos profissionais; o tempo necessário para realizá-las; e avaliando holisticamente os níveis produtivos diários, semanais, mensais e anuais (Rosa, Mimura \& Borges, 2019; Martins \& Antunes, 2019).

Com preparo e embasamento em evidências científicas, o Enfermeiro deve distribuir a carga de trabalho, utilizando o tempo necessário para atividades que realmente precisem ser desempenhadas pela mão de obra qualificada e realocando serviços menos complexos que podem ser feitos por outros profissionais. Além deste dimensionamento de pessoal, o Enfermeiro deve estar atento à necessidade real de novas contratações para o setor, a fim de manter bons níveis de produção e processamentos de qualidade (Rosa, Mimura \& Borges, 2019; Martins \& Antunes, 2019).

Ademais, o gestor do CME deve analisar holisticamente tudo que é inerente aos processamentos utilizados, pois até a embalagem escolhida para empacotar os produtos que passam pela reesterilização colabora para o aumento do tempo despendido nesta atividade e dos custos (Vital, Miranda, Nagliate \& Vasconcelos, 2016). Como abordado no estudo A10, a embalagem de produtos para saúde feito com campos de tecido de algodão são, expressivamente, mais caras do que as embalagens feitas com o papel grau cirúrgico. Isto se deve ao fato da necessidade de reprocessamento do campo de tecido e, ainda, tempo utilizado para empacotar os materiais com o tecido ser bem maior que quando se utiliza o papel grau cirúrgico.

Para a decisão do melhor tipo de embalagem, o gestor do CME deve considerar, de acordo com seus serviços, os materiais, o quantitativo, a necessidade de abastecimento e, associado a isso, deve realizar a comparação de modo real para conhecer os custos verdadeiros, livrando-se de pensamentos enraizados contra o uso de embalagens descartáveis. Deve ser considerado, também, que o tecido de algodão sofre desgastes ao longo dos processamentos, levando à necessidade de novas aquisições, além de necessitar passar pela etapa de lavagem, antes da autoclavação. Ou seja, o papel grau cirúrgico, por sua vez, não apresentará nenhum destes fatores de desgaste, visto que não passa pelo reprocessamento e ainda conta com um menor tempo de preparo do pacote para esterilizar (Pereira et al., 2020).

É importante mencionar, ainda, que o tempo de validade do processo de esterilização nos pacotes embalados com grau cirúrgico é maior que a validade dos pacotes embalados com tecido. Neste sentido, reafirma-se que o grau cirúrgico é um tipo de embalagem mais viável e com menores custos em relação aos campos de tecido de algodão (Araujo, Reisdorfer, Silva, Soder \& Santos, 2016).

O reprocessamento dos instrumentais cirúrgicos não utilizados foram mencionados, pelos estudos A04, A07 e A11, como gastos evitáveis em CME. É sabido que, com base na Resolução da Diretoria Colegiada (RDC) $n^{\circ} 30$ de 15 de fevereiro de 2006 da Agência Nacional de Vigilância Sanitária (ANVISA), os materiais que foram abertos não podem ser, apenas, reesterilizados, devendo, portanto, passar por todo o processamento, iniciado pela limpeza e finalizado no armazenamento devido (Marraschi, Cocco, Gaspar, Vedovato \& Boaventura, 2017). Assim, o reprocessamento de materiais que foram abertos e não utilizados foi destacado como gasto desnecessário relacionado ao CME.

Nesta questão, percebe-se que é essencial que haja uma boa comunicação e interação entre as equipes do CME e do Centro Cirúrgico, visto que, a maioria dos materiais reprocessados é oriundo de instrumentais cirúrgicos que estão em caixas que são abertas, mas não são utilizados no procedimento. É recomendado que ocorra uma remodelação da composição das caixas cirúrgicas, revisando cada instrumental contido, retirando os desnecessários e adicionando apenas os necessários à cirurgia para qual a caixa é destinada (Santos et al., 2017).

É importante ressaltar que a reorganização das caixas cirúrgicas não traz benefícios apenas quando reduz o número de reprocessamentos de instrumentais não utilizados, mas também na diminuição do tempo de trabalho (retrabalho) dos 
profissionais com estes materiais (Schneider, Anzanello, Pirovano \& Fogliatto, 2018), já que a mão de obra foi apontada como destacada forma de custo nos estudos A02 e A05.

Ainda tratando-se de reprocessamento, o estudo A08 trouxe o prazo de validade expirado e a presença de resíduo orgânico pós-esterilização como as duas principais causas de reprocessamentos de produtos para saúde. Sabe-se que o prazo de validade do processo de esterilização vai de acordo com o tipo de embalagem utilizado para acondicionar o material. Neste sentido, é importante que o técnico responsável pelo arsenal (diariamente) verifique o prazo de validade de cada embalagem e garanta que as que possuem prazo de validade mais apertado sejam utilizadas primeiro (Maciel, Martins, Mendes, KozusnyAndreani \& Souza, 2019).

Aponta-se o sistema informatizado como adequado para facilitar o gerenciamento dos produtos para saúde, corroborando para controle de custos, manutenções e até novas aquisições, quando necessárias. Além disso, essa informatização possibilita acompanhar o produto, o prazo de validade do processamento, controlar os reprocessamentos, minimizar os gastos relacionados à perda da integridade da embalagem por danos nas etiquetas e reduzir o tempo de trabalho dos profissionais na etapa de montagem dos produtos (Martins \& Ribeiro, 2017).

Com relação aos materiais que precisam ser reprocessados por presença de resíduo orgânico pós-esterilização, é preciso destacar que indicam falha profissional durante a limpeza e inspeção dos materiais (Alcântara et al., 2019), fato este que, desnecessariamente, eleva os custos do CME. Sendo assim, o processo de educação continuada constante se faz necessário para que os gastos evitáveis não sejam uma realidade no serviço, considerando que o detergente enzimático utilizado na limpeza possui valor monetário elevado e todas as demais etapas do processamento de esterilização implicam custos que serão desperdiçados, pois os materiais passarão novamente por todas as etapas, visto que a etapa base de limpeza não foi feita corretamente e isso compromete todas as demais (Farias et al., 2016).

O estudo A09 explanou os custos relacionados ao CME, de acordo com a forma de abastecimento dos produtos para saúde. Foi visto que, nesta investigação, ao comparar os custos de três diferentes formas de abastecimento (Materiais processados em CME da própria instituição; Materiais processados em CME contratada - terceirizada; e materiais descartáveis) de materiais de terapia respiratória, foi visto que o abastecimento deste Hospital feito por produtos descartáveis foi o mais dispendioso, enquanto a aquisição e processamento em CME próprio da instituição representou a forma com menores custos. $\mathrm{O}$ abastecimento pelo CME externo foi mais caro em relação ao processamento em CME próprio, mas foi mais rentável em relação à aquisição de produtos descartáveis.

No entanto, é importante destacar que se faz essencial que cada CME, em sua gestão, analise os custos aplicados em mão de obra e em insumos que são necessários para a concretização dos processamentos, para então comparar com os valores dos processamentos terceirizados e/ou aquisição produtos descartáveis (Costa, Montenegro, Silva \& Filho, 2020; Pereira et al., 2020). Este estudo ressalta que cada CME deve ter domínio dos seus gastos, conhecê-los intimamente para, então, avaliar de modo concreto a opção mais rentável para si.

Ademais, quando trata-se de terceirização dos serviços de esterilização, é importante ter em mente que a instituição que terceiriza este serviço não tem o controle das etapas que envolvem o processo de esterilização e nem da qualidade do reprocessamento do material. E, sendo o CME, o setor de importância ímpar para a prestação de serviços de qualidade e, ainda, muito importante na prevenção e controle de infecções, a avaliação do custo versus benefício de não se ter um CME dentro da instituição se faz necessária (Gonçalves et al., 2020; Druck, 2016).

De forma paralela aos principais resultados, os estudos A02 e A03 mencionaram a manutenção de equipamentos como fator importante para o gerenciamento do CME, pois é de extrema importância para a eficácia dos processamentos. Tal manutenção, caso não seja feita periodicamente, torna-se cara, caso seja feita a partir de algum defeito apresentado pela máquina. Para o sucesso dos processamentos, é crucial que os equipamentos utilizados para tal estejam em seu perfeito estado de 
funcionamento, logo, é necessário que o gestor do CME se atente à manutenção periódica dos equipamentos, visto que a manutenção preventiva é mais rentável do que a manutenção corretiva (Valério \& Teixeira, 2018).

Diante do exposto, pode-se concluir que as instituições hospitalares devem ter um gerenciamento de seus custos, a fim de que os gastos sejam controlados sem que o nível de qualidade assistencial seja atingido. Estas instituições devem sempre estar avaliando seus custos, pois é notório que qualquer mudança em suas rotinas e/ou surgimento de novas patologias cuidadas/abraçadas pela instituição podem onerar seus gastos (Vieira \& Bento, 2016).

É esclarecido, portanto, que o gerenciamento de custos em CME exige uma base fortalecida de conhecimentos sobre todos os aspectos relacionados às atividades do setor. Como ferramentas, o gestor pode fazer uso do método de custeio baseado em atividades, pois permite o acesso e análise de custos por atividade realizada no CME que, por vezes, são pouco visualizadas (Vasconcelos et al., 2017; Vital et al., 2016). Este método permite que o enfermeiro gestor conheça os gastos inerentes aos processos realizados, fornecendo evidências claras e precisas que direcionem o gerenciamento. Por conseguinte, corrobora para que custos desnecessários sejam percebidos e excluídos, bem como aponta para que o enfermeiro, com seu conhecimento técnicocientífico, analise e tome decisões para o melhor funcionamento do setor (Souza \& Cunha, 2020).

A prática diária do enfermeiro de centro de esterilização mostra que o mapeamento de etapas das atividades realizadas no setor também é positivo no contexto do CME e assemelha-se ao método de custeio baseado em atividades. Trata-se da construção de um mapa com as etapas do processo desejado. No CME, o mapeamento das etapas de processamento de produtos é uma forma de conhecer cada atividade realizada e os custos inerentes, favorecendo a avaliação e controle dos recursos necessários e disponíveis (Zeferino, Sarantopoulos, Spagnol, Min \& Freitas, 2019).

O presente estudo possibilitou um vislumbre sobre as pesquisas relacionadas aos custos originados em centro de material e esterilização (setor que é por muitos profissionais e pesquisadores identificado como o coração e o pulmão das instituições de saúde). Porém, para a decepção dos autores deste trabalho, se verificou que muito pouco é investigado e publicado sobre como conhecer (métodos) os gastos relacionados às complexas atividades que compõem cada etapa dos processos que ocorrem diariamente em um CME.

Destaca-se o enfermeiro como gestor do CME, porque tem em suas mãos o poder de exercer papel central ao pesquisar e tornar conhecido e passível de maior controle os processos e custos relacionados ao setor onde atua; além de auxiliar todo corpo profissional para que se apropriem de seus conhecimentos e deveres para que se obtenha excelência no serviço e, ainda, criar uma boa interação com a equipe do CME e dos demais setores, a fim de facilitar todo o trabalho desempenhado.

\section{Conclusão}

O gerenciamento de custos em Centro de Material e Esterilização é essencial para a rotina da instituição hospitalar, com vistas a um adequado planejamento e controle de recursos financeiros, humanos e materiais aplicados, evitando o desperdício destes e direcionando-os para os serviços necessários. Para tal gerenciamento, é preciso conhecer precisamente a rotina da instituição hospitalar, buscando adequar-se à real necessidade e peculiaridades do CME e instituição correspondente.

Evidencia-se que os custos são particulares e inerentes a cada instituição e cada setor, porque estão intimamente relacionados às atividades neles desenvolvidas e às suas práticas diárias. Assim, o enfermeiro necessita, corriqueiramente, conhecer e analisar os custos oriundos de seu CME para que possa otimizá-los sem perder a qualidade da assistência prestada. Além disso, os enfermeiros precisam contar com atualizações constantes a respeito dos conteúdos englobados ao CME com o intuito de contribuir para o melhor desempenho do setor, bem como possuir domínio de gestão e controle de despesas visando assegurar um funcionamento eficaz e com qualidade das atividades realizadas no setor em conjunto com redução dos custos para a unidade de saúde. 
Por conseguinte, é notório que os artigos que abordam os processos realizados no CME são escassos e, principalmente, quando direcionados para os aspectos de custos, logo, é primordial um aprofundamento acerca do tema, com o desenvolvimento de estudos com maior nível de evidência científica, investigando as atividades que representam gastos evitáveis para o setor, bem como as melhores formas de minimizá-los, salientando que os estudos devem ser feitos de modo personalizado, pois cada CME é dotado de suas peculiaridades.

Para a Enfermagem, evidenciar a necessidade de conhecimento de custos em CME representa um dos fatores que podem trazer a devida atenção à importância deste setor, assim como destacar o Enfermeiro com seu crucial papel de gestor deste local que é palco para o desenvolvimento de atividades tão importantes quanto as assistenciais diretas ao paciente.

\section{Referências}

Alcântara, I., Freitas, R. D. de, Pinheiro, L. G., Felipe, A. T. P., Rebouças, P. D., \& Santo, I. C. J. Z. dos. (2019). Eficácia de diferentes processos de desinfecção em turbinas de alta rotação. Journal of Health \& Biological Sciences. 7(2), 177-181. https://pesquisa.bvsalud.org/portal/resource/pt/biblio-1005752. 10.12662/2317-3076jhbs.v7i2.2511.p177-181.2019

Alvim, A. L., Ramos, M. S., \& Durão, P. M. S. (2019). Monitoramento da limpeza de produtos para saúde com teste adenosina trifosfato. Revista SOBECC, 24(2), 57-61. https://revista.sobecc.org.br/sobecc/article/view/496. 10.5327/Z1414-4425201900020002

Alvim, A. L. S., \& Souza, K. F. de. (2018). Causas de retrabalho de produtos para saúde no centro de materiais e esterilização. Revista SOBECC, 23(1), 36. https://revista.sobecc.org.br/sobecc/article/view/263. 10.5327/Z1414-4425201800010002

Botazini, N. O., \& Carvalho, R. de. (2017). Cancelamento de cirurgias: uma revisão integrativa da literatura. Revista SOBECC, 22(4), 230244. https://docs.bvsalud.org/biblioref/2017/12/876633/sobecc-v22n4_pt_230-244.pdf. 10.5327/Z1414-4425201700040008

Camargo, F. C., Iwamoto, H. H., Galvão, C. M., Pereira, G. A., Andrade, R. B., \& Masso, G. C. (2018). Competences and Barriers for the Evidence-Based Practice in Nursing: an integrative review. Revista Brasileira de Enfermagem, 71(4), 2148-2156. https://www.scielo.br/scielo.php?script=sci_arttext\&pid=S0034-71672018000402030. 10.1590/0034-7167-2016-0617

Cardoso, A. A. B., Souza, L. M. de., Reis, A. O., \& Palha, V. M. (2020). Gestão de custos em organizações hospitalares: sistemática por centro de custos. Semina: Ciências Sociais e Humanas, 41(1), 123-138. http://www.uel.br/revistas/uel/index.php/seminasoc/article/view/39793. 10.5433/1679-0383.2020v41n1p123

Cavalcante, F. M. L., \& Barros, L. M. (2020). O trabalho do enfermeiro no centro de material e esterilização: uma revisão integrativa. Revista SOBECC, 25(3), 171-178. https://revista.sobecc.org.br/sobecc/article/view/580. 10.5327/10.5327/Z1414-4425202000030007

Costa, R. da., Montenegro, H. R. A., Silva, R. N. da., \& Filho, A. J. A. (2020). Papel dos trabalhadores de enfermagem no centro de material e esterilização: revisão integrativa. Escola Anna Nery Revista de Enfermagem, 24(3), 1-13. scielo.br/pdf/ean/v24n3/1414-8145-ean-24-3-e20190316.pdf. 10.1590/2177-9465ean-2019-0316

Druck, G. (2016). A terceirização na saúde pública: formas diversas de precarização do trabalho. Trabalho, Educação e Saúde, 14(1), 1543. https://www.scielo.br/pdf/tes/v14s1/1678-1007-tes-14-s1-0015.pdf. 10.1590/1981-7746-sol00023

Farias, I. P., Caldas, C. M., Miranda, L. N., Nagliate, P. de C., Freitas, D. A., \& Vasconcelos, E. L. (2016). Educação continuada em centro de material e esterilização: percepção da equipe de enfermagem. Revista de enfermagem da UFPE on line, 10(7), 26042610. https://periodicos.ufpe.br/revistas/revistaenfermagem/article/view/11320. 10.5205/1981-8963-v10i7a11320p2604-2610-2016

Gonçalves, R. C. da S., Sé, A. C. S., Pezzi, M. da C. S., Pinto, C. M. I., Souza, P. A. de., Fernández, B. M., Hernández, P. E., \& Tonini, T. (2020). Atividades de enfermagem para o diagnóstico "Risco para contaminação de artigos". Research, Society and Development, 9(9). https://rsdjournal.org/index.php/rsd/article/view/7794. 10.33448/rsd-v9i9.7794

Graziano, K. U., Laranjeira, P. R., Silva, L. C. da F. e., Bronzatti, A. G., Souza, R. Q. de., Moriya, G. A. de A., \& Psaltikidis, E. M. (2017). Critérios para avaliação de novas tecnologias para esterilização. Revista SOBECC, 22(3), 171-177. https://docs.bvsalud.org/biblioref/2017/09/859113/sobecc-v22n3_pt_171177.pdf. 10.5327/Z1414-4425201700030009

Jericó, M. de C., \& Castilho, V. (2010). Gerenciamento de custos: aplicação do método de Custeio Baseado em Atividades em Centro de Material Esterilizado. Revista da Escola de Enfermagem da Universidade de São Paulo, 44(3), 745-752. https://www.scielo.br/pdf/reeusp/v44n3/28.pdf. 10.1590/S008062342010000300028

Ludke, M. \& Andre, M. E . D. A. (2013). Pesquisas em educação: uma abordagem qualitativa. E.P.U.

Maciel, Y. K. Q., Martins, C. C., Mendes, E. C. B., Kozusny-Andreani, D. I., \& Souza, T. F. Q. de. (2019). Prazo de validade de esterilização de artigos utilizados em uma clínica odontológica. Revista Nursing, 22(250), 2794-2799. https://pesquisa.bvsalud.org/portal/resource/pt/biblio-998160.

Marraschi, V., Cocco, A. C., Gaspar, A. R., Vedovato, C. A., \& Boaventura, A. P. (2017). Avaliação e controle de instrumentais utilizados em sala operatória durante cirurgias torácicas. Revista SOBECC, 22(3), 123-130. https://docs.bvsalud.org/biblioref/2017/09/859099/sobecc-v22n3_pt_123130.pdf. 10.5327/Z1414-4425201700030002

Martins, J. F., \& Antunes, A. V. (2019). Staff sizing in the material and sterilization center of a university hospital. Revista da Escola de Enfermagem da USP, 53. https://www.scielo.br/scielo.php?pid=S0080-62342019000100477\&script=sci_arttext. 10.1590/s1980-220x2018027703496 
Martins, F. de O. e S., \& Ribeiro, M. L. L. (2017). Implantação e uso de sistema de rastreabilidade automatizado em central de materiais e esterilização. Revista SOBECC, 22(1), 52-58. https://docs.bvsalud.org/biblioref/2017/05/833449/sobecc-v22n1_pt_52-58.pdf. 10.5327/Z1414-4425201700010009

Miranda, A. R., Pinheiro, M. G., \& Silva, E. R. da. (2019). O processo de trabalho no centro de material e esterilização: percepção da equipe de enfermagem. Revista Científica de Enfermagem, 9(27), 33-45. https://www.recien.com.br/index.php/Recien/article/view/300.

Morais, L. M. C. de., Queiroga, S. S., Santos, A. N., Oliveira, J. M. D. de., \& Melo, J. T. da S. (2018). Processo de esterilização sob a ótica dos profissionais do centro de material e esterilização. Revista SOBECC, 23(2), 61-68. https://revista.sobecc.org.br/sobecc/article/view/262. 10.5327/Z1414-4425201800020002

Oliveira, A. C. de., \& Mati, M. L. (2017). Indicações e limitações dos diferentes detergentes utilizados no processamento de produtos para a saúde. Revista SOBECC, 22(2), 106-114. https://revista.sobecc.org.br/sobecc/article/view/162/0. 10.5327/Z1414-4425201700020008

Paula, J. R. de A., Silva, R. de C. R. da., Vedovato, C. A., \& Boaventura, A. P. (2015). Instrumentais nas caixas cirúrgicas: avaliação de custo. REVISTA SOBECC, 20(2), 73-80. http://www.sobecc.org.br/arquivos/artigos/2015/pdfs/v20n2/73-80.pdf. 10.5327/Z1414-4425201500020003

Pereira, R. R. N., Pascoal, L. M., Rolim, I. L. T. P., Ferreira, A. G. N., \& Silva, E. L. da. (2020). Custo de processamento de produtos para saúde: uma revisão integrativa. Revista SOBECC, 25(2), 105-113. https://revista.sobecc.org.br/sobecc/article/view/569. 10.5327/Z1414-4425202000020007

Perroca, M. G. P., Jericó, M. de C., \& Facundin, S. D. (2007). Cancelamento cirúrgico em um hospital escola: implicações sobre o gerenciamento de custos. Revista Latino-americana de Enfermagem, 15(5). https://www.revistas.usp.br/rlae/article/view/2485/2918.

Pinheiro, S. L., Vasconcelos, R. O., Oliveira, J. L. C. de., Matos, F. G. de O. A., Tonini, N. S., \& Alves, D. C. I. (2017). Taxa de cancelamento cirúrgico: indicador de qualidade em hospital universitário público. Revista Mineira de Enfermagem,21, 18. https://cdn.publisher.gn1.link/reme.org.br/pdf/e1014.pdf. 10.5935/1415-2762.20170024

Pompeo, D. A., Rossi, L. A., \& Galvão, C. M. (2009). Revisão integrativa: etapa inicial do processo de validação de diagnóstico de enfermagem. Acta Paulista de Enfermagem, 22(4), 434-438. https://www.scielo.br/pdf/ape/v22n4/a14v22n4.pdf. 10.1590/S0103-21002009000400014

Reisdorfer, N., Araujo, G. M. de, Silva, L. A. A. da, Santos, A. M. dos, \& Soder, R. M. (2016). Segurança do paciente: embalagens, acondicionamento e tempo de guarda de materiais esterilizados na Atenção Básica. Ciência, Cuidado E Saúde, 15(4), 662-668. http://periodicos.uem.br/ojs/index.php/CiencCuidSaude/article/view/29925. https://doi.org/10.4025/cienccuidsaude.v15i4.29925

Rosa, N. T., Mimura, V. A., \& Borges, E. C. P. (2019). Carga de trabalho e dimensionamento dos profissionais de enfermagem no centro de material de esterilização. Revista Nursing, 22(250), 2775-2782. https://pesquisa.bvsalud.org/portal/resource/pt/biblio-998124.

Santos, A. B. dos., Calandrim, L. F., Bidurim, J. M. M., Gonçalves, R. A., Vedovato, C. A., \& Boaventura, A. P. (2017). Avaliação da utilização de instrumentais cirúrgicos em um centro cirúrgico ambulatorial. Revista SOBECC, 22(2), 76-81. https://docs.bvsalud.org/biblioref/2017/08/848189/sobecc-v22n2_pt_7681.pdf. 10.5327/Z1414-4425201700020004

Santos, G. A. A. C. dos., \& Bocchi, S. C. M. (2017). Cancellation of elective surgeries in a Brazilian public hospital: reasons and estimated reduction. Revista Brasileira de Enfermagem [Internet], 70(3), 561-568. https://www.scielo.br/scielo.php?pid=S0034-71672017000300535\&script=sci_arttext. 10.1590/00347167-2016-0084

Schneider, D. S. dos S., Anzanello, M. J., Pirovano, R. S. V., \& Fogliatto, F. S. (2018). Sistemática para racionalização de instrumentais de bandejas cirúrgicas. Revista SOBECC, 23(1), 52-58. https://revista.sobecc.org.br/sobecc/article/view/375. 10.5327/Z1414-4425201800010009

Silva, C. C. da., Savian, C. M., Prevedello, B. P., Zamberlan, C., Dalpian, D. M., \& Santos, B. Z. dos. (2020). Acesso e utilização de serviços odontológicos por gestantes: revisão integrativa de literatura. Ciência \& Saúde Coletiva, 25(3), 827-835. https://www.scielo.br/pdf/csc/v25n3/1413-8123-csc-25-030827.pdf. 10.1590/1413-81232020253.01192018

Silva, J. M. B. da., Loureiro, L. H., Silva, I. C. M. da., \& Novaes, M. L. (2020). Coronavírus e os protocolos de desinfecção e reprocessamento de artigos hospitalares. Research, Society and Development, 9(9), e29996187. https://rsdjournal.org/index.php/rsd/article/view/6187. 10.33448/rsd-v9i9.6187

Souza, M. P. M. de., \& Cunha, C. L. F. (2020). Avaliação do uso do método de custeio baseado em atividade no ambiente hospitalar: uma revisão de literatura. Revista Médica de Minas Gerais, 30, e-3010. http://www.rmmg.org/artigo/detalhes/2660. 10.5935/2238-3182.20200021

Souza, M. T. de., Silva, M. D. da., \& Carvalho, R. de. (2010). Integrative review: what is it? How to do it?. Einstein, 8(1), 102106. https://www.scielo.br/pdf/eins/v8n1/pt_1679-4508-eins-8-1-0102.pdf. 10.1590/s1679-45082010rw1134

Souza, W. R. de., Spiri, W. C., Lima, S. A. M., Bernardes, A., \& Luppi, C. H. B. (2015). Utilização do custeio baseado em atividades em centro de material e esterilização como ferramenta gerencial. Revista Eletrônica de Enfermagem [Internet], 17(2), 290301. https://revistas.ufg.br/fen/article/view/27540/19577. 10.5216/ree.v17i2.27540

Stipanich, C., Goulardins, J. B., Medeiros, M. Maria, F., \& Tanaka, C. (2018). Comparação de custos em diferentes processos de abastecimento de materiais de fisioterapia respiratória em um hospital público de porte extra. Revista Pesquisa em Fisioterapia,8(2), 230238. https://www5.bahiana.edu.br/index.php/fisioterapia/article/view/1927. 10.17267/2238-2704rpf.v8i2.1927

Tomé, M. F., \& Lima, A. F. C. (2015). Mapeamento do processo de reprocessamento de campos cirúrgicos de tecido de algodão. Revista SOBECC, 20(4), 197201. http://www.sobecc.org.br/arquivos/artigos/2015/pdfs/v20n4/197-201.pdf. 10.5327/Z1414-4425201500040003

Valério, D., \& Teixeira, E. P. (2018, outubro). Gestão da manutenção dos equipamentos de um centro de material esterilizado de pequeno porte: qualidade, planejamento e oportunidades. XIII WORKSHOP DE PÓS-GRADUAÇÃO E PESQUISA DO CENTRO PAULA SOUZA, São Paulo, SP, Brasil, $2175-1897$.

Vasconcelos, E. L., Solvas, J. F. G., Sousa, A. A. D. de., Trindade, R. F. C. da., Almeida, T. G. de, \& Comassetto, I. (2017). Uso do sistema de custo baseado $\mathrm{em}$ atividades para gerenciar a esterilização de materiais. Revista de enfermagem da UFPE on-line, 11(4), 16581663. https://pesquisa.bvsalud.org/portal/resource/pt/bde-31306. 10.5205/reuol.10438-93070-1-RV.1104sup201707 
Research, Society and Development, v. 10, n. 4, e4810413652, 2021

(CC BY 4.0) | ISSN 2525-3409 | DOI: http://dx.doi.org/10.33448/rsd-v10i4.13652

Vieira, G. C. G., \& Bento, L. A. (2016). Gestão de custos hospitalares:o conhecimento do enfermeiro. Revista UNINGÁ, 48(1), 5660. http://revista.uninga.br/index.php/uninga/article/view/1284/904.

Vital, J. S., Miranda, L. N., Nagliate, P C., \& Vasconcelos, E. L. (2016). Análise de custos de embalagens para esterilização utilizando custeio baseado em atividades. Revista de enfermagem UFPE on-line, 10(8), 2877-2885. https://periodicos.ufpe.br/revistas/revistaenfermagem/ article/view/11356/13079. 10.5205/1981-8963-v10i8a11356p2877-2885-2016

Zeferino, E. B. B., Sarantopoulos, A., Spagnol, G. S., Min, L. L., \& Freitas, M. I. P. de. (2019). Mapa de Fluxo de Valor: aplicação e resultados na central de desinfecção. Revista Brasileira de Enfermagem [Internet], 72(1), 148-155. https://www.scielo.br/pdf/reben/v72n1/pt_0034-7167-reben-72-010140.pdf. 10.1590/0034-7167-2018-0517 